\title{
Utilitarianism or Welfarism: Does it Make a Difference? *
}

\author{
Patrick Moyes \\ GREThA, CNRS, UMR 5113 \\ Université de Bordeaux \\ $\&$ \\ Nicolas Gravel \\ AMSE (GREQAM) \\ Aix-Marseille University
}

\section{Cahiers du GREThA}

$n^{\circ}$ 2011-30

\author{
GRETHA UMR CNRS 5113 \\ Université Montesquieu Bordeaux IV \\ Avenue Léon Duguit - 33608 PESSAC - FRANCE \\ Tel : +33 (0)5.56.84.25.75 - Fax : +33 (0)5.56.84.86.47 - www.gretha.fr
}




\title{
Utilitarisme ou Welfarisme: Quelle Différence?
}

\section{Résumé}

Nous montrons qu'il est possible de concilier les principes de l'unanimité utilitariste et de l'unanimité welfariste dès lors que l'ensemble des profils, sur lesquels le consensus doit être atteint, est suffisamment riche. Plus précisément, nous identifions une condition de fermeture qui, si elle est vérifiée par la classe des $n$-uplets de fonctions d'utilité, garantit que les classements des états sociaux induits par l'unanimité utilitariste et l'unanimité welfariste sur cette même classe sont identiques. Nous illustrons l'importance de ce résultat pour la mesure des inégalités unidimensionnelles et multidimensionnelles en terme de dominance.

Mots-clés : Unanimité, Utilitarisme, Welfarisme, Dominance Stochastique

\section{Utilitarianism or Welfarism: Does it Make a Difference?}

\begin{abstract}
We show that it is possible to reconcile the utilitarian and welfarist principles under the requirement of unanimity provided that the set of profiles over which the consensus is attained is rich enough. More precisely, we identify a closedness condition which, if satisfied by a class of $n$-tuples of utility functions, guarantees that the rankings of social states induced by utilitarian and welfarist unanimities over that class are identical. We illustrate the importance of the result for the measurement of unidimensional as well as multidimensional inequalities from a dominance point of view.
\end{abstract}

Keywords: Unanimity, Utilitarianism, Welfarism, Stochastic Dominance

JEL: D31, D63, I32

Reference to this paper: MOYES Patrick, GRAVEL Nicolas (2011) Utilitarianism or Welfarism: Does it Make a Difference? Cahiers du GREThA, $\mathrm{n}^{\circ} 2011-30$.

http://ideas.repec.org/p/grt/wpegrt/2011-30.html.

* This paper forms part of the research project The Multiple Dimensions of Inequality (Contract No. ANR 2010 BLANC 1808) of the French National Agency for Research whose financial support is gratefully acknowledged. We are indebted to Stephen Bazen, Peter Lambert and two anonymous referees for very useful comments and suggestions when preparing this version. Needless to say, none of the persons mentioned above should be held responsible for remaining deficiencies. 


\section{Introduction and Motivation}

We investigate in this paper the conditions under which the application of unanimity to two well-known principles in normative economics - utilitarianism and welfarism - leads to the same ranking of the social states under comparison. Following Sen (1977, 1979b,a), welfarism is the name given to the normative approaches that rank social states on the sole basis of the distribution of welfare levels achieved by individuals in those states. Hence two social states that generate the same distribution of individual well-being are considered equivalent by any welfarist approach, even when the two states differ substantially in other respects. Most welfarist approaches value individual well-beings positively and treat individuals in a symmetric manner: a society's welfare increases when its members' well-beings do so and does not change as the result of a permutation of the individuals' well-beings. Utilitarianism, which compares social states on the basis of the sum of the individual well-beings, is by far the most widely used of the welfarist approaches. For instance the optimal taxation model initiated by Mirrlees (1971) relies heavily on the utilitarian social welfare function when determining the properties of the tax schedule. The utilitarian rule and extensions of it have been extensively used in optimal growth theory and in population ethics: see e.g. the recent contributions of Blackorby, Bossert, and Donaldson (2005) for the former and of Basu and Mitra (2007) for the latter. Of particular relevance for the present paper is the recognition that utilitarianism has also been given a prominent role in the dominance analysis of distributional issues, be it of the one-dimensional type initiated by Kolm (1969) and Atkinson (1970), or of the multidimensional variety following the work of Kolm (1977) and Atkinson and Bourguignon (1982). ${ }^{1}$

Despite this preeminence, utilitarianism has been criticised on different grounds, the most serious of which being its insensitivity to the distribution of the total sum of the individuals' well-beings (see e.g. Sen (1973)). Equity-concerned approaches like the maximin and the leximin, which give priority to the less privileged members of the society, may appear to that extent more appropriate for ranking social states. From a less extreme point of view, welfarist approaches that allow for some trade-off between the total sum of individual well-beings and its distribution, like for instance the mean of order $r$ principles (see e.g. Blackorby and Donaldson (1982)), can arguably be preferred to utilitarianism from an ethical point of view. As emphasised by Dasgupta, Sen, and Starrett (1973), a further limitation of utilitarianism is that it builds on the assumption of additive separability which is a strong condition to impose on a general social welfare function. This assumption rules out a number of social welfare functions that may be considered potential candidates for assessing a society's achievements.

It may be argued that the success of utilitarianism originates in its simplicity and tractability. Substituting more ethically appealing social welfare functions like generalised means for the utilitarian rule in the optimum taxation model would result in such an increase in complexity that the model would soon become untractable. Similarly, equivalence results in the stochastic dominance literature rely heavily on utilitarianism and it is far from clear whether

1 The analysis of income distribution issues from a dominance point of view, which finds its origin in Hardy, Littlewood, and Pólya (1934), has given rise during the last forty years to a considerable literature among which are Hadar and Russell (1969), Whitmore (1970), Rothschild and Stiglitz (1973), Le Breton (1987), Shorrocks and Foster (1987), Foster and Shorrocks (1988) just to mention a few. The multidimensional stochastic dominance literature - initiated by Hadar and Russell (1974) - has gone in different directions, ranging from comparisons of income distributions for heterogeneous populations (see e.g. Atkinson and Bourguignon (1987), Jenkins and Lambert (1993), Bazen and Moyes (2003), Bourguignon (1989), Fleurbaey, Hagneré, and Trannoy (2003), Gravel and Moyes (2010)) to the ranking of intergenerational mobility matrices (Atkinson (1981), Van de gaer (1993) among others). 
they would continue to hold when more flexible social welfare functions are used. For sure Dasgupta et al. (1973) have shown that both the specific utilitarian approach and the more general welfarist ones lead to the same dominance criteria in the special case where all individuals have the same utility function and income is the only variable entering the utility function. But the question arises in a more general setting as to what is lost when one appeals to utilitarianism rather than to less specific welfarist principles to justify particular dominance criteria. We show in this paper that actually nothing is lost when the consensus is sought among all utilitarian social welfare functions - the application of unanimity in both cases will lead to the same ranking of social states - provided that the class of utility functions over which this consensus is looked for verifies a closedness condition with respect to specific functional compositions. We also illustrate the strength of the closedness condition by providing several familiar examples of domains of $n$-tuples of utility functions that satisfy this property as well as a few examples that do not.

The model we consider is fairly standard and it is presented in Section 2. Typically, it consists in comparing social states on the basis of the distributions of utilities they generate. Yet it takes the cautious view that the utility functions that generate the distributions of well-being in every state are not known but rather belong to some suitably large class. It therefore permits one to compare two social states only when the distributions of utilities in those states are ranked in the same way for all $n$-tuples of utility functions in the class. We introduce in Section 3 the two welfare principles that will be used for comparing the social states: utilitarian unanimity and welfarist unanimity. Section 4 contains our main results and presents two closedness conditions, which if satisfied by the classes of $n$-tuples of utility functions, guarantee that the rankings of the social states by the utilitarian and welfarist unanimities coincide. We exhibit instances of classes of $n$-tuples of utility functions that verify or violate these conditions in Section 5. We provide some interpretation of our results as well as a discussion of seemingly related results in the literature in Section 6. Finally Section 7 contains concluding remarks.

\section{The Framework}

It is convenient to think of an ethical observer who is in charge of the evaluation of the society's welfare in the different states of the world. This evaluation process involves two successive stages: (i) in a first stage the ethical observer attributes to every individual and every social state a level of well-being by means of a utility function, and (ii) in a second stage she uses the distribution of the individuals' well-beings to determine the overall society's welfare. This fiction should not be taken too literally and it is amenable to at least two different interpretations as far as the first stage of the evaluation process is concerned. First, it is compatible with the stricto sensu welfarist approach according to which the utility function is the one actually used by the individual in order to derive her well-being. ${ }^{2}$ Here, well-being is assumed to be a cardinally measurable and interpersonally comparable variable and the utility function reflects the individual's personal tastes and values. But the utility function can also be viewed as reflecting the assessment of the individual's situation by the ethical observer as it is typically assumed in the extended sympathy approach. Then, well-being summarises all the aspects of an individual's situation that are considered relevant for normative evaluation by the ethical observer There is no presumption that utility is connected to the individual's

2 We refer the reader to Blackorby et al. (2005) and Griffin (1986) for discussions of the welfarist approach in economics and philosophy, respectively. 
actual well-being and one must rather interpret the utility function as a predefined social norm. It is immaterial for our purpose which of these two approaches one has in mind and our results apply equally in both cases (for more on this see Gravel and Moyes (2011, Section $3)$ ). In the second stage the ethical observer is assumed to compute the society's well-being by aggregating the individuals' well-beings by means of a social welfare function which captures the ethical observer's value judgements.

We consider a finite population consisting of $n$ individuals $(n \geqq 2)$. A situation - or more generally a social state - is an element $\mathbf{s} \in \mathscr{X}$ where $\mathscr{X}$ indicates the set of relevant social states. It is not necessary for the time being to make precise what the set $\mathscr{X}$ looks like. For instance, $\mathscr{X}$ may consist of a finite collection of social states, or it can be a convex subset of $\mathbb{R}^{m}$, where $m \geqq 1$. We assume that $\mathbf{s}$ provides a complete description of all the features that are deemed relevant for normative evaluation. This encompasses a number of possibilities some of which will be examined in a later stage. The utility achieved by individual $i$ in state $\mathbf{s}$ as envisaged by the ethical observer - be she welfarist or not - is indicated by $U_{i}(\mathbf{s})$, where $U_{i}$ is the utility function assigned to her. An $n$-tuple of utility functions - or equivalently, a profile - is a list $\boldsymbol{U}:=\left(U_{1}, \ldots, U_{n}\right) \in \mathscr{U}:=\mathscr{U}_{1} \times \cdots \times \mathscr{U}_{n}$, where $\mathscr{U}_{i}$ represents the set of admissible utility functions for individual $i$. We use $\boldsymbol{U}(\mathbf{s}):=\left(U_{1}(\mathbf{s}), \ldots, U_{n}(\mathbf{s})\right)$ to indicate the distribution of utility - or equivalently, of well-being - generated by the social state $\mathbf{s} \in \mathscr{X}$ when the profile is $\boldsymbol{U} \in \mathscr{U}$. We assume cardinal full comparability, which means that it makes sense to compare utility levels and utility differences between individuals as well as for the same individual. This implies that the individuals' utility functions are defined up to the same increasing affine transformation: the profiles $\boldsymbol{U}$ and $\boldsymbol{V}$ convey the same information whenever $V_{i}(\mathbf{s})=\alpha+\beta U_{i}(\mathbf{s})(\alpha \in \mathbb{R}, \beta>0)$, for all $i \in\{1,2, \ldots, n\}$ and all $\mathbf{s} \in \mathscr{X}$ (see e.g. d'Aspremont and Gevers (2002), Roemer (1996, Chapter 1)). ${ }^{3}$

\section{Utilitarianism, Welfarism and Unanimity}

The utilitarian rule ranks the social states under comparison on the basis of the sum of the utilities they generate. More precisely, a utilitarian ethical observer endowed with the profile $\boldsymbol{U} \in \mathscr{U}$ considers $\mathbf{s}^{*}$ to be no worse than $\mathbf{s}^{\circ}$ if and only if $\sum_{i=1}^{n} U_{i}\left(\mathbf{s}^{*}\right) \geqq \sum_{i=1}^{n} U_{i}\left(\mathbf{s}^{\circ}\right)$. The profile $\boldsymbol{U}$ summarises the utilitarian ethical observer's normative judgement and it is the only information by which such ethical observers can be distinguished. In order to achieve a degree of robustness in the evaluation, it is common practice to require that a reasonably large class of such ethical observers unanimously agree on the ranking of the two social states under comparison. We formally define this requirement of utilitarian unanimity as follows:

Utilitarian UnANimity Rule. We say that the social state $\mathbf{s}^{*}$ is no worse than the social state $\mathbf{s}^{\circ}$ for the utilitarian unanimity rule over the class $\mathscr{U}^{*} \subset \mathscr{U}$, if and only if

$$
\sum_{i=1}^{n} U_{i}\left(\mathbf{s}^{*}\right) \geqq \sum_{i=1}^{n} U_{i}\left(\mathbf{s}^{\circ}\right), \forall \boldsymbol{U} \in \mathscr{U}^{*}
$$

The utilitarian unanimity rule allows us to encompass different value judgements whose spectrum is fully captured by the subset $\mathscr{U}^{*}$ of admissible $n$-tuples of utility functions. Much of

3 While utilitarianism only requires cardinal unit comparability - only utility differences need to be comparable between individuals - other principles like the maximin necessitate that comparisons of utility levels between individuals be meaningful. In order to avoid discarding any potentially relevant principle, we impose the stronger informational structure of cardinal full comparability of which cardinal unit comparability is a particular case. 
the discussion in the literature addresses the question of what constitutes the relevant set of utility profiles over which one is looking for unanimity. These discussions typically require that some additional structure be imposed on the set $\mathscr{X}$ of social states.

However the utilitarian rule is just one among many possible principles that can be used for aggregating individual utility levels. It has been criticised on the grounds that it pays no attention to the way utilities are distributed among the individuals. By contrast, principles such as the maximin and the leximin attach the greatest attention to the distribution of utility and only value those changes that benefit the worst-off persons. Less demanding principles that lie somewhere in between these extreme principles and utilitarianism are also conceivable. A formal way to handle all these principles consists in stating that the normative value of the social state $\mathbf{s} \in \mathscr{X}$ is given by $G(\boldsymbol{U}(\mathbf{s})):=G\left(U_{1}(\mathbf{s}), \ldots, U_{n}(\mathbf{s})\right)$, where $G: \mathbb{R}^{n} \longrightarrow \mathbb{R}$ is the social welfare function. The utilitarian rule has the property that social welfare is not affected when two individuals exchange their utility levels: in other words, it does not matter who has which utility. It is natural to confine our attention to those social welfare functions with the property that a society's welfare is not affected by a permutation of utilities among its members. Formally, the social welfare function $G$ is symmetric if $G(P \mathbf{u}) \geq G(\mathbf{u})$, for all distributions of utilities $\mathbf{u}=\left(u_{1}, \ldots, u_{n}\right)$ and all $n \times n$ permutation matrices $P$ and we denote as $\mathscr{G}$ the set of symmetric social welfare functions. We say that social state $\mathbf{s}^{*}$ is no worse than social state $\mathbf{s}^{\circ}$ for an ethical observer endowed with the profile $\boldsymbol{U} \in \mathscr{U}$ and the social welfare function $G \in \mathscr{G}$, if and only if $G\left(\boldsymbol{U}\left(\mathbf{s}^{*}\right)\right) \geqq G\left(\boldsymbol{U}\left(\mathbf{s}^{\circ}\right)\right)$.

As we did for utilitarianism, we avoid relying on a particular profile when determining the distributions of well-being in the first stage of the evaluation process. Similarly, it would make sense to take an agnostic position as to the choice of the appropriate social welfare function used to compute the society's welfare starting with the distribution of well-being among its members. This leads one naturally to adopt a particularly cautious - but on the other hand definitively uncontroversial - position that consists in requiring unanimous agreement among all welfarist ethical observers who subscribe to some general value judgements. We define formally the welfarist unanimity rule as follows:

Welfarist UnANimity Rule. We say that situation $\mathbf{s}^{*}$ is no worse than situation $\mathbf{s}^{\circ}$ for the welfarist unanimity rule over the class of profiles $\mathscr{U}^{*} \subset \mathscr{U}$ and the class of social welfare functions $\mathscr{G}^{*} \subset \mathscr{G}$, if and only if

$$
G\left(\boldsymbol{U}\left(\mathbf{s}^{*}\right)\right) \geqq G\left(\boldsymbol{U}\left(\mathbf{s}^{\circ}\right)\right), \forall \boldsymbol{U} \in \mathscr{U}^{*}, \forall G \in \mathscr{G}^{*}
$$

Here, the universality of the value judgements that form the basis of this consensual approach is fully reflected by the class of profiles $\mathscr{U}^{*}$ and the class of social welfare functions $\mathscr{G}^{*}$. Suppose that all ethical observers - be they utilitarian or welfarist - consider that the relevant class of profiles is $\mathscr{U}^{*}$. Then, the question arises to know how the imposition of the additional requirement that unanimity holds for all social welfare functions in the class $\mathscr{G}^{*}$ will affect the ranking of the social states by the utilitarian principle.

\section{Main Results}

Since the social welfare function $G\left(u_{1}, \ldots, u_{n}\right)=\sum_{i=1}^{n} u_{i}$ belongs to $\mathscr{G}$, it is clear that welfarist unanimity over the class $\mathscr{G}$ implies utilitarian unanimity for any class $\mathscr{U}^{*}$ of profiles. It is interesting that utilitarian unanimity may also imply the a priori more demanding welfarist unanimity when the class of profiles is closed under specific functional composition. For later 
use, we define formally this property of closedness of a class $\mathscr{U}^{*}$ of profiles under functional composition as follows.

Closedness Under Functional Composition. The class of profiles $\mathscr{U}^{*}$ is closed under functional composition by the class of functions $\boldsymbol{\Psi}^{*} \subseteq \boldsymbol{\Psi}:=\{\psi: \mathbb{R} \longrightarrow \mathbb{R}\}$ if:

$$
\forall \boldsymbol{U}:=\left(U_{1}, \ldots, U_{n}\right) \in \mathscr{U}^{*} ; \psi \in \boldsymbol{\Psi}^{*} \Longrightarrow \psi \circ \boldsymbol{U}:=\left(\psi \circ U_{1}, \ldots, \psi \circ U_{n}\right) \in \mathscr{U}^{*} .
$$

Intuitively, imposing the condition of closedness under functional composition amounts to requiring that the class of admissible profiles is reasonably rich. Obviously, the richness of the class of admissible profiles is related to the size of the class of functions with respect to which it is assumed to be closed. The larger - with respect to set inclusion - is the class of functions used in the composition, the richer the class of admissible profiles.

In order to illustrate the meaning of this condition in specific contexts, we first consider the case where the ethical observer is only concerned with efficiency and does not express any particular preference regarding the way utilities are distributed among the society's members. The concern for efficiency is typically captured by the requirement that the social welfare does not decrease when - other things equal - the utility of one individual increases. Formally, we say that the social welfare function $G: \mathbb{R}^{n} \longrightarrow \mathbb{R}$ is non-decreasing if $G(\mathbf{u}) \geq G(\mathbf{v})$, for all $\mathbf{u}=\left(u_{1}, \ldots, u_{n}\right), \mathbf{v}=\left(v_{1}, \ldots, v_{n}\right) \in \mathbb{R}^{n}$ such that $u_{i} \geqq v_{i}$, for all $i=1,2, \ldots, n$, and we let

$$
\mathscr{G}_{1}:=\left\{G: \mathbb{R}^{n} \longrightarrow \mathbb{R} \mid G \text { is symmetric and non-decreasing }\right\} .
$$

Given two distributions of individual utilities $\mathbf{u}:=\left(u_{1}, \ldots, u_{n}\right)$ and $\mathbf{v}:=\left(v_{1}, \ldots, v_{n}\right)$, let us denote respectively as $\left.\mathbf{u}_{(}\right)$and $\left.\mathbf{v}_{(}\right)$their non-decreasing rearrangements defined by $u_{(1)} \leqq$ $u_{(2)} \leqq \cdots u_{(n)}$ and $v_{(1)} \leqq v_{(2)} \leqq \cdots v_{(n)}$. Then, we say that $\mathbf{u}$ rank order dominates $\mathbf{v}$, which we write as $\mathbf{u} \geq_{R O} \mathbf{v}$, if and only if

$$
u_{(i)} \geqq v_{(i)}, \forall k=1,2, \ldots, n .
$$

The rank-order dominance criterion - also known as the Suppes dominance criterion in the literature - has been repeatedly used in normative analysis (see e.g. Blackorby and Donaldson (1977), Madden (1996), Saposnik (1983)). ${ }^{4}$ The next result establishes the equivalence between the ranking of utility distributions by the rank order criterion and the one resulting from the application of unanimity over the class of symmetric and non-decreasing social welfare functions.

Lemma 4.1. Let $\mathbf{u}, \mathbf{v} \in \mathbb{R}^{n}$. Then, the following two statements are equivalent:

(a) $\mathbf{u} \geq_{R O} \mathbf{v}$.

(b) $G(\mathbf{u}) \geqq G(\mathbf{v})$, for all $G \in \mathscr{G}_{1}$.

Proof. ${ }^{5}$ That statement (a) is sufficient for (b) to hold follows from the definition of rank order dominance and the assumptions that the social welfare function $G$ is symmetric and non-

4 Throughout the paper we find convenient to present our results within the inverse stochastic dominance framework based on the comparisons of the quantile - equivalently inverse cumulative distribution - functions of the distributions of utilities. We could equally frame our approach in terms of stochastic dominance criteria which involve the comparisons of the cumulative distribution functions and their successive integrals. As far as we are concerned, this does not make any difference since both approaches produce the same ranking of social states at the first and second orders which we restrict our attention to.

5 There exist different proofs of this - pretty obvious - result in the literature that must be acknowledged. For instance Lemma 4.1 is a direct consequence of Saposnik (1981, Proposition 1). The problem is that his proof is indirect and makes use at some stage of the utilitarian social welfare function, something we would specifically like to avoid. 
decreasing. To prove the converse implication, choose the positional social welfare functions $G^{k}\left(u_{1}, \ldots, u_{n}\right):=u_{(k)}$, for $k=1,2, \ldots, n$, all of which are symmetric and non-decreasing.

Given the above result, it is now possible to identify the closedness condition which when imposed on the class of profiles guarantees that the rankings of situations by the utilitarian and welfarist unanimities coincide. More precisely, letting $\boldsymbol{\Psi}_{1}:=\{\psi \in \boldsymbol{\Psi} \mid \psi: \mathbb{R} \longrightarrow$ $\mathbb{R}$ is non-decreasing\}, we obtain:

Proposition 4.1. Let $\mathscr{U}^{*} \subseteq \mathscr{U}$. Then, a sufficient condition for

$$
\sum_{i=1}^{n} U_{i}\left(\mathbf{s}^{*}\right) \geqq \sum_{i=1}^{n} U_{i}\left(\mathbf{s}^{\circ}\right), \forall \boldsymbol{U} \in \mathscr{U}^{*},
$$

to be equivalent to

$$
G\left(\boldsymbol{U}\left(\mathbf{s}^{*}\right)\right) \geqq G\left(\boldsymbol{U}\left(\mathbf{s}^{\circ}\right)\right), \forall \boldsymbol{U} \in \mathscr{U}^{*}, \forall G \in \mathscr{G}_{1},
$$

for any $\mathbf{s}^{*}, \mathbf{s}^{\circ} \in \mathscr{X}$, is that

$$
\forall \boldsymbol{U}:=\left(U_{1}, \ldots, U_{n}\right) \in \mathscr{U}^{*} ; \psi \in \boldsymbol{\Psi}_{1} \Longrightarrow \psi \circ \boldsymbol{U}:=\left(\psi \circ U_{1}, \ldots, \psi \circ U_{n}\right) \in \mathscr{U}^{*}
$$

Proof. It follows from the definitions that the welfarist unanimity principle implies the utilitarian unanimity principle whatever the class of utility functions. Therefore, given $\mathscr{U}^{*} \subseteq$ $\mathscr{U}$, we have to establish that (4.6) is a sufficient condition for (4.4) to imply (4.5), for all $\mathbf{s}^{*}, \mathbf{s}^{\circ} \in \mathscr{X}$, when $\boldsymbol{\Psi}^{*}=\boldsymbol{\Psi}_{1}$. Actually, given Lemma 4.1, we have to prove that, if (4.6) is satisfied for $\Psi^{*}=\Psi_{1}$, then the existence of a profile $\boldsymbol{U} \in \mathscr{U}^{*}$ and a pair of social states $\mathbf{s}^{*}, \mathbf{s}^{\circ} \in \mathscr{X}$ such that $\neg\left[\boldsymbol{U}\left(\mathbf{s}^{*}\right) \geq_{R O} \boldsymbol{U}\left(\mathbf{s}^{\circ}\right)\right]$ entails that (4.4) does not hold. Suppose that there exists a profile $\boldsymbol{U} \in \mathscr{U}^{*}$ and two social states $\mathbf{s}^{*}, \mathbf{s}^{\circ} \in \mathscr{X}$ such that $\neg\left[\boldsymbol{U}\left(\mathbf{s}^{*}\right) \geq_{R O} \boldsymbol{U}\left(\mathbf{s}^{\circ}\right)\right]$, and let $k^{*}$ be the smallest index $k \in\{1,2, \ldots, n\}$ such that

$$
\begin{aligned}
& U_{(i)}\left(\mathbf{s}^{*}\right) \geqq U_{(i)}\left(\mathbf{s}^{\circ}\right), \forall i=1,2, \ldots, k^{*}-1, \text { and } \\
& U_{\left(k^{*}\right)}\left(\mathbf{s}^{*}\right)<U_{\left(k^{*}\right)}\left(\mathbf{s}^{\circ}\right),
\end{aligned}
$$

where $U_{(1)}\left(\mathbf{s}^{*}\right) \leqq U_{(2)}\left(\mathbf{s}^{*}\right) \leqq \cdots \leqq U_{(n)}\left(\mathbf{s}^{*}\right)$ and $U_{(1)}\left(\mathbf{s}^{\circ}\right) \leqq U_{(2)}\left(\mathbf{s}^{\circ}\right) \leqq \cdots \leqq U_{(n)}\left(\mathbf{s}^{*}\right)$. Such an index $k^{*}$ necessarily exists and we have

$$
U_{\left(k^{*}\right)}\left(\mathbf{s}^{*}\right) \leqq U_{\left(k^{*}+1\right)}\left(\mathbf{s}^{*}\right) \leqq \cdots \leqq U_{(q)}\left(\mathbf{s}^{*}\right)<U_{\left(k^{*}\right)}\left(\mathbf{s}^{\circ}\right)
$$

where $q:=\max \left\{i \mid U_{i}\left(\mathbf{s}^{*}\right)<U_{\left(k^{*}\right)}\left(\mathbf{s}^{\circ}\right)\right\}$. Consider now the function $\psi$ defined by

$$
\psi(s):=\left\{\begin{aligned}
0, & \forall s<U_{\left(k^{*}\right)}\left(\mathbf{s}^{\circ}\right), \\
1, & \forall U_{\left(k^{*}\right)}\left(\mathbf{s}^{\circ}\right) \leqq s
\end{aligned}\right.
$$

which is non-decreasing and, therefore, belongs to the class $\boldsymbol{\Psi}_{1}$. By definition of $\psi$ we have

$$
\sum_{i=1}^{n} \psi \circ U_{i}\left(\mathbf{s}^{*}\right)=\sum_{i=1}^{n} \psi \circ U_{(i)}\left(\mathbf{s}^{*}\right)<\sum_{i=1}^{n} \psi \circ U_{(i)}\left(\mathbf{s}^{\circ}\right)=\sum_{i=1}^{n} \psi \circ U_{i}\left(\mathbf{s}^{\circ}\right) .
$$

Invoking condition (4.6) we know that $\psi \circ \boldsymbol{U}:=\left(\psi \circ U_{1}, \ldots, \psi \circ U_{n}\right) \in \mathscr{U}^{*}$. We have exhibited a profile $\boldsymbol{V} \in \mathscr{U}^{*}$ such that $\sum_{i=1}^{n} V_{i}\left(\mathbf{s}^{*}\right)<\sum_{i=1}^{n} V_{i}\left(\mathbf{s}^{\circ}\right)$, and the proof is complete. 
Hence, if the class of admissible profiles $\mathscr{U}^{*}$ is closed under functional composition by the class of all non-decreasing functions, then the ranking of situations provided by welfarist unanimity over all symmetric and non-decreasing social welfare functions and all admissible profiles coincides with that implied by utilitarian unanimity over the same class of profiles.

We now turn to establishing a similar result for the case where welfarist unanimity is restricted to those social welfare functions that exhibit - in addition to a preference for more efficient distributions of utilities - some aversion to inequality in utility. The standard way to express this aversion is through the property of Schur-concavity (see e.g. Kolm (1969), Dasgupta et al. (1973), Marshall and Olkin (1979) and Marshall, Olkin, and Arnold (2011)). Formally, we say that the social welfare function $G: \mathbb{R}^{n} \longrightarrow \mathbb{R}$ is Schur-concave if $G(B \mathbf{u}) \geqq$ $G(\mathbf{u})$, for all $\mathbf{u}=\left(u_{1}, \ldots, u_{n}\right) \in \mathbb{R}^{n}$ and all bistochastic matrices $B$ (see Marshall and Olkin (1979), Marshall et al. (2011)). We note incidently that, since the set of bistochastic matrices comprises the permutation matrices, a Schur-concave function is symmetric, and we let

$$
\mathscr{G}_{2}:=\left\{G: \mathbb{R}^{n} \longrightarrow \mathbb{R} \mid G \text { is non-decreasing and Schur-concave }\right\} .
$$

It is well-known that the ranking of utility vectors by means of non-decreasing and Schurconcave social welfare functions is connected to the ranking generated by the generalised Lorenz criterion (see Kolm (1969) and Shorrocks (1983)). We recall that u generalised Lorenz dominates $\mathbf{v}$, which we write as $\mathbf{u} \geq_{G L} \mathbf{v}$, if and only if

$$
\frac{1}{n} \sum_{i=1}^{k} u_{(i)} \geqq \frac{1}{n} \sum_{i=1}^{k} v_{(i)}, \forall k=1,2, \ldots, n .
$$

An interesting result for our purpose is the fact that the rankings of the distributions of utilities by the welfarist unanimity rule and the generalised Lorenz quasi-ordering prove to be identical under certain conditions, as it is indicated below.

Lemma 4.2. Let $\mathbf{u}, \mathbf{v} \in \mathbb{R}^{n}$. Then, the following two statements are equivalent:

(a) $\mathbf{u} \geq_{G L} \mathbf{v}$.

(b) $G(\mathbf{u}) \geqq G(\mathbf{v})$, for all $G \in \mathscr{G}_{2}$.

Proof. ${ }^{6}$ Suppose that $\mathbf{u} \geq_{G L} \mathbf{v}$, which upon invoking Marshall and Olkin (1979, $2 \mathrm{~B} 1$ and 5A9) implies that there exists a distribution of utilities $\mathbf{w} \in \mathbb{R}^{n}$ and a $n \times n$ bistochastic matrix $B$ such that $\mathbf{u}=B \mathbf{w}$ and $\mathbf{w} \geq \mathbf{v}$. That statement (a) implies statement (b) follows from the assumption that $G$ is non-decreasing and Schur-concave. To prove the converse implication, choose the partial sums social welfare functions $G^{k}\left(u_{1}, \ldots, u_{n}\right):=\sum_{j=1}^{k} u_{(j)}$, for $k=1,2, \ldots, n$, all of which are non-decreasing and Schur-concave.

We are now in a position to identify the closedness condition to be imposed on the class of utility functions that guarantees that the ranking of situations implied by the utilitarian unanimity is identical to that resulting from the welfarist unanimity restricted to the class of non-decreasing and Schur-concave social welfare functions. More precisely, letting $\boldsymbol{\Psi}_{2}:=\{\psi \in$ $\Psi \mid \psi: \mathbb{R} \longrightarrow \mathbb{R}$ is non-decreasing and concave $\},{ }^{7}$ we obtain:

6 To be sure, Lemma 4.2 is a direct consequence of Shorrocks (1983, Theorem 2), who built upon Dasgupta et al. (1973, Theorem 1). Once again, the problem with this way of arguing is that it makes use at some stage of the utilitarian social welfare function, something we precisely would like to dispense with.

7 A function $\psi: \mathbb{R} \longrightarrow \mathbb{R}$ is concave if $\psi((1-\lambda) u+\lambda v) \geqq(1-\lambda \psi(u)+\lambda \psi(v))$, for all $u, v \in \mathbb{R}$ and all $\lambda \in[0,1]$. 
Proposition 4.2. Let $\mathscr{U}^{*} \subseteq \mathscr{U}$. Then, a sufficient condition for

$$
\sum_{i=1}^{n} U_{i}\left(\mathbf{s}^{*}\right) \geqq \sum_{i=1}^{n} U_{i}\left(\mathbf{s}^{\circ}\right), \forall \boldsymbol{U} \in \mathscr{U}^{*},
$$

to be equivalent to

$$
G\left(\boldsymbol{U}\left(\mathbf{s}^{*}\right)\right) \geqq G\left(\boldsymbol{U}\left(\mathbf{s}^{\circ}\right)\right), \forall \boldsymbol{U} \in \mathscr{U}^{*}, \forall G \in \mathscr{G}_{2},
$$

for any $\mathbf{s}^{*}, \mathbf{s}^{\circ} \in \mathscr{X}$, is that

$$
\forall \boldsymbol{U}:=\left(U_{1}, \ldots, U_{n}\right) \in \mathscr{U}^{*} ; \psi \in \boldsymbol{\Psi}_{2} \Longrightarrow \psi \circ \boldsymbol{U}:=\left(\psi \circ U_{1}, \ldots, \psi \circ U_{n}\right) \in \mathscr{U}^{*} .
$$

ProOF. We already know that the welfarist unanimity principle implies the utilitarian unanimity principle whatever the class of utility functions. Therefore, given $\mathscr{U}^{*} \subseteq \mathscr{U}$ and $\mathbf{s}^{*}, \mathbf{s}^{\circ} \in \mathscr{X}$, we have to establish that (4.15) is a sufficient condition for (4.13) to imply (4.14), when $\boldsymbol{\Psi}^{*}=\boldsymbol{\Psi}_{2}$. Actually, given Lemma 4.2, we have to prove that, if (4.1) is satisfied for $\boldsymbol{\Psi}^{*}=\boldsymbol{\Psi}_{2}$, then the existence of a profile $\boldsymbol{U} \in \mathscr{U}^{*}$ and a pair of social states $\mathbf{s}^{*}, \mathbf{s}^{\circ} \in \mathscr{X}$ such that $\neg\left[\boldsymbol{U}\left(\mathbf{s}^{*}\right) \geq_{G L} \boldsymbol{U}\left(\mathbf{s}^{\circ}\right)\right]$ entails that (4.13) does not hold. Suppose that there exists a profile $\boldsymbol{U} \in \mathscr{U}^{*}$ and two social states $\mathbf{s}^{*}, \mathbf{s}^{\circ} \in \mathscr{X}$ such that $\neg\left[\boldsymbol{U}\left(\mathbf{s}^{*}\right) \geq_{G L} \boldsymbol{U}\left(\mathbf{s}^{\circ}\right)\right]$, and let $k^{*}$ be the smallest index $k \in\{1,2, \ldots, n\}$ such that

$$
\begin{aligned}
\sum_{i=1}^{k} U_{(i)}\left(\mathbf{s}^{*}\right) & \geqq \sum_{i=1}^{k} U_{(i)}\left(\mathbf{s}^{\circ}\right), \forall k=1,2, \ldots, k^{*}-1, \text { and } \\
\sum_{i=1}^{k^{*}} U_{(i)}\left(\mathbf{s}^{*}\right) & <\sum_{i=1}^{k^{*}} U_{(i)}\left(\mathbf{s}^{\circ}\right),
\end{aligned}
$$

which implies that $U_{\left(k^{*}\right)}\left(\mathbf{s}^{*}\right)<U_{\left(k^{*}\right)}\left(\mathbf{s}^{\circ}\right)$. Such an index $k^{*}$ necessarily exists and we have

$$
U_{\left(k^{*}\right)}\left(\mathbf{s}^{*}\right) \leqq U_{\left(k^{*}+1\right)}\left(\mathbf{s}^{*}\right) \leqq \cdots \leqq U_{(q)}\left(\mathbf{s}^{*}\right)<U_{\left(k^{*}\right)}\left(\mathbf{s}^{\circ}\right)
$$

where $q:=\max \left\{i \mid U_{i}\left(\mathbf{s}^{*}\right)<U_{\left(k^{*}\right)}\left(\mathbf{s}^{\circ}\right)\right\}$. Consider now the function $\psi$ defined by

$$
\psi(s):=\left\{\begin{array}{cl}
s, & \forall s<U_{\left(k^{*}\right)}\left(\mathbf{s}^{\circ}\right), \\
U_{\left(k^{*}\right)}\left(\mathbf{s}^{\circ}\right), & \forall U_{\left(k^{*}\right)}\left(\mathbf{s}^{\circ}\right) \leqq s,
\end{array}\right.
$$

which is non-decreasing and concave, and therefore belongs to the class $\boldsymbol{\Psi}_{2}$. From the definition of $\psi$ we have

$$
\sum_{i=1}^{n} \psi \circ U_{i}\left(\mathbf{s}^{*}\right)=\sum_{i=1}^{n} \psi \circ U_{(i)}\left(\mathbf{s}^{*}\right)<\sum_{i=1}^{n} \psi \circ U_{(i)}\left(\mathbf{s}^{\circ}\right)=\sum_{i=1}^{n} \psi \circ U_{i}\left(\mathbf{s}^{\circ}\right) .
$$

Invoking condition (4.15) we know that $\psi \circ \boldsymbol{U}:=\left(\psi \circ U_{1}, \ldots, \psi \circ U_{n}\right) \in \mathscr{U}^{*}$. We have therefore exhibited a profile $\boldsymbol{V} \in \mathscr{U}^{*}$ such that $\sum_{i=1}^{n} V_{i}\left(\mathbf{s}^{*}\right)<\sum_{i=1}^{n} V_{i}\left(\mathbf{s}^{*}\right)$, which makes the proof complete.

Thus, for the ranking of situations provided by welfarist unanimity over all non-decreasing and Schur-concave social welfare functions and all admissible profiles to coincide with that implied by utilitarian unanimity over the same class of profiles it is sufficient that the latter is closed under functional composition by the class of all non-decreasing and concave functions. 
This result is still valid when $G$ is non-decreasing, symmetric and concave or quasi-concave because Lemma 4.2 continues to hold for this restricted class of social welfare functions.

The two results above indicate that in order to obtain an equivalence between utilitarian and welfarist unanimities, it is sufficient that the class of profiles under consideration be closed under the application of a specific transformation to all utility functions. In the case of Proposition 4.1 the transformation must be non-decreasing, while in the case of Proposition 4.2 it must also be concave. It is helpful to consider the simplest distributional problem where a given amount of income has to be distributed among the society's members. In the utilitarian model the concern for greater equality is fully accommodated by the concavity of the utility function common to all individuals. By contrast, the welfarist rules impose a double concern for less inequality captured by the Schur-concavity of the social welfare function and the concavity of the utility function. What we learn from Proposition 4.2 is that the additional concern for equality of the welfarist approach captured by the Schur-concavity of the social welfare function has no incidence on the ranking of situations that results from the application of utilitarian unanimity over the class of concave utility functions. It must be emphasised that the property that defines the class of functions with respect to which the class of profiles of utility functions is closed is tightly connected to the property of the social welfare function $G$, which is assumed to be, either symmetric and non-decreasing (Proposition 4.1), or nondecreasing and Schur-concave (Proposition 4.2). Therefore, the classes of profiles that ensure that utilitarian and welfarist unanimities rank the social states in the same way appear to be conditional upon the class of social welfare functions that have been selected.

It is also worth noting that these two results do not impose any restriction on the $n$-tuples of individual utility functions. In particular, the utility functions of the society's members need not be identical contrary to what is typically assumed in the standard stochastic dominance literature. Nor is it important whether the individuals are considered to be selfish - they only care about their own situation - or not. Our model allows for the possibility that an individual's well-being in a given social state depends on her situation as well as on the situations of the other individuals in the society. Moreover, a glance at Propositions 4.1 and 4.2 suggests that no restriction whatsoever is placed on the set of social states $\mathscr{X}$, as it is usually done in conventional dominance analysis and as will be assumed in the examples considered in the next section. Actually, one must be cautious as a close inspection of the proofs reveals that this is not always the case.

Certainly, no particular structure has to be imposed on the set of social states for Proposition 4.1 to hold. This is because in the proofs we only work with the social states $\mathbf{s}^{*}, \mathbf{s}^{\circ}$ and the corresponding distributions of utilities given the profile $\boldsymbol{U}$. This is no longer true for Proposition 4.2 because in order to prove Lemma 4.2 we need to introduce an additional distribution of utilities $\mathbf{w}$, and we have to make sure that, given the profile $\boldsymbol{U}$, there exists a social state $\tilde{\mathbf{s}} \in \mathscr{X}$ such that $\mathbf{w}=\boldsymbol{U}(\tilde{\mathbf{s}}), \mathbf{u}=B \mathbf{w}$ and $\mathbf{w} \geq \mathbf{v}$, for some bistochastic matrix $B$. This requirement imposes some structure on the set of social states as well as on the class of admissible $n$-tuples of utility functions. One possibility is to assume that, given the profile $\boldsymbol{U}$ and any distribution of utility $\mathbf{u}$ in a closed, comprehensive and convex subset of $\mathbb{R}^{n}$, there always exists a social state $\mathbf{s} \in \mathscr{X}$ such that $\mathbf{u}=\boldsymbol{U}(\mathbf{s})$. Note that this does not imply that the set $\mathscr{X}$ is a convex subset of $\mathbb{R}^{m}$. However, at least one dimension has to be continuous in order to ensure that any distribution of utility can be associated with a social state. A typical example is the model considered by Gravel and Moyes (2010), where a social state indicates for each individual her income (the continuous variable) and her health (a categorical variable). 


\section{Some Examples}

While Propositions 4.1 and 4.2 identify two closedness conditions - to be satisfied by the class of profiles - that are sufficient for guaranteeing that the rankings of the social states by the utilitarian and the welfarist unanimities coincide, they do not tell how restrictive these conditions are. We examine this question in the light of Proposition 4.2 by considering several important examples borrowed from the literature on unidimensional and multidimensional dominance analysis. All these examples have in common that the set of social states has a particular structure: typically $\mathscr{X}=\mathbb{R}^{m}$ where $m=n q$ for some $q \geqq 1$. In order to simplify the exposition we assume henceforth that the different functions used are differentiable to the required order.

Example 5.1. Comparisons of Income Distributions Across Homogenous PopuLATIONS. Let $\mathscr{X}=\mathbb{R}_{++}^{n}$ and interpret a social state as a distribution of income between the $n$ individuals in society. Assume moreover that all individuals derive utility from their own income by means of an identical utility function so that $U_{i}(\mathbf{s})=U\left(x_{i}\right)$, where $x_{i}>0$ is the income of individual $i$ in social state $\mathbf{s}:=\left(x_{1}, \ldots, x_{n}\right) .{ }^{8}$ Assume further that the utility function is non-decreasing and concave, hence

$$
U^{\prime}(y) \geqq 0 \text { and } U^{\prime \prime}(y) \leqq 0, \forall y>0,
$$

where $U^{\prime}(y)$ and $U^{\prime \prime}(y)$ are respectively the first and second derivatives of $U$ evaluated at the income level $y$, and let $\mathscr{U}^{*}$ be the class of $n$-tuples of such identical individual utility functions. Now let $V(y)=\psi(U(y))$, for all $y>0$, where $\psi$ is non-decreasing and concave. It can be checked that

$$
\begin{aligned}
& V^{\prime}(y)=\psi^{\prime}(U(y)) U^{\prime}(y) \geqq 0, \forall y>0, \text { and } \\
& V^{\prime \prime}(y)=\psi^{\prime \prime}(U(y)) U^{\prime}(y)^{2}+\psi^{\prime}(U(y)) U^{\prime \prime}(y) \leqq 0, \forall y>0,
\end{aligned}
$$

so that $\mathscr{U}^{*}$ is closed under functional composition by all non-decreasing and concave functions $\psi$. The rankings of income distributions by utilitarian unanimity and welfarist unanimity are therefore identical here, and they both coincide with the rankings provided by the generalised Lorenz criterion or, equivalently, by second degree stochastic dominance (see e.g. Shorrocks (1983) and Fishburn and Vickson (1978), respectively).

Example 5.2. Comparisons of Income Distributions Across Heterogenous PopUlations: CASE 1. A typical instance is the case where a social state indicates for each individual her income and health. Then we have $\mathscr{X}=\mathbb{R}_{++}^{2 n}$ and a social state is a vector $\mathbf{s}:=\left(\left(x_{1}, \theta_{1}\right), \ldots,\left(x_{n}, \theta_{n}\right)\right)$, where $x_{i}>0$ and $\theta_{i} \in \mathbb{R}$ are respectively the income and health of individual $i$. We assume that individual well-being depends on the person's health and income only, is non-decreasing with income at a rate that is non-increasing with respect to health: the healthier the individual, the smaller her increase in utility due to an additional amount of income. Another example is provided by the distribution of income among households who differ in size and composition. In this case, the household's well-being is assumed to be nondecreasing with income in such a way that the marginal utility of income does not increase

8 Although we use the same symbol in order to save notation, it must be realised that the utility functions $U_{i}$ and $U$ are of different nature and must not be confused. The same remark applies to our subsequent examples and it will not be repeated. 
with family size (see Atkinson and Bourguignon (1987)). ${ }^{9}$ In either of these interpretations, it is assumed that all individuals or households have the same utility function. Considering the first interpretation, we have $U_{i}(\mathbf{s})=U\left(x_{i}, \theta_{i}\right)$, and we assume that

$$
\begin{aligned}
& U_{y}(y, \theta) \geqq 0, \forall y>0, \forall \theta \in \mathbb{R}, \text { and } \\
& U_{y \theta}(y, \theta) \leqq 0, \forall y>0, \forall \theta \in \mathbb{R},
\end{aligned}
$$

where $U_{y}(y, \theta)$ is the first derivative of $U(y, \theta)$ with respect to income $y$ and $U_{y \theta}(y, \theta)$ the cross-derivative. Suppose that there exists $\psi$ such that $V(y, \theta)=\psi(U(y, \theta))$, for all $y>0$ and all $\theta \in \mathbb{R}$, where $\psi$ is non-decreasing and concave. Denoting respectively as $V_{y}(y, \theta)$ and $V_{y \theta}(y, \theta)$ the first derivative with respect to income and the cross-derivative of $V(y, \theta)$, we obtain:

$$
\begin{aligned}
& V_{y}(y, \theta)=\psi^{\prime}(U(y, \theta)) U_{y}(y, \theta) \text { and } \\
& V_{y \theta}(y)=\psi^{\prime \prime}(U(y, \theta)) U_{\theta}(y, \theta) U_{y}(y, \theta)+\psi^{\prime}(U(y, \theta)) U_{y \theta}(y, \theta) .
\end{aligned}
$$

While $V_{y}(y, \theta) \geqq 0$, for all $y>0$ and all $\theta \in \mathbb{R}$, we cannot be sure that $V_{y \theta}(y, \theta) \leqq 0$ in all circumstances. Hence the domain $\mathscr{U}^{*}$ of profiles considered in this setting is not closed under functional composition by all non-decreasing and concave functions. Indeed, conditions (5.3a) and (5.3b) together with the assumption that $\psi$ is non-decreasing and concave do not guarantee that $V_{y \theta}(y)$ be non-positive. Therefore the utilitarian and welfarist principles do not coincide when unanimity is sought over the class of profiles verifying conditions (5.3a) and (5.3b). Suppose now we require in addition that

$$
U_{\theta}(y, \theta) \geqq 0, \forall y>0, \forall \theta \in \mathbb{R},
$$

as proposed by Bazen and Moyes (2003). In other words, the better is her health, the greater an individual's well-being, or the smaller the family size, the greater the household's welfare. We note incidently that the latter interpretation of condition (5.5) is less natural than the former and open to debate. If we now take $\mathscr{U}^{*}$ to be the class of all $n$-tuples of identical individual utility functions satisfying conditions (5.3a), (5.3b) and (5.5), then it can be checked that this class is closed under functional composition by all non-decreasing and concave functions. As a result, the application of utilitarian and welfarist unanimities over the class of profiles $\mathscr{U}^{*}$ will lead to the same conclusion: that provided by the bidimensional first order stochastic dominance criterion (see Bazen and Moyes (2003), Gravel and Moyes (2010)).

Example 5.3. Comparisons of Income Distributions Across Heterogenous PopUlations: CASE 2. Suppose as in Bourguignon (1989) that $U(y, \theta)$ verifies conditions (5.3a), (5.3b), (5.5), and is in addition concave in income, so that

$$
U_{y y}(y, \theta) \leqq 0, \forall y>0, \forall \theta \in \mathbb{R}
$$

where $U_{y y}(y, \theta)$ is the second derivative of $U(y, \theta)$ with respect to income (see also Gravel and Moyes (2010)). Let $\mathscr{U}^{*}$ represent the class of $n$-tuples of utility functions satisfying all these conditions. It is closed under functional composition by all non-decreasing and concave

9 Admittedly, the notion of household well-being has given rise to different interpretations (see Shorrocks (2004), Blackorby and Donaldson (1993), Ebert (2004), Ebert and Moyes (2009), Fleurbaey, Hagneré, and Trannoy (2007) among others). One may think of $\theta_{i}=\psi\left(m_{i}\right)$ as an index of household $i$ 's ability to produce well-being that is decreasing with its size $m_{i}$. 
functions. Therefore, the application of utilitarian unanimity over the class $\mathscr{U}^{*}$ generates the same ranking of social states as the one induced by welfarist unanimity over the same class of profiles and for all non-decreasing and Schur-concave social welfare functions.

Example 5.4. Comparisons of Finite Intertemporal Income Streams. There is a finite horizon $n$ and a social state indicates the income received by the individual in each period $i$ of her lifetime. Here, the index $i$ refers to the date at which a given individual lives rather than to a distinct individual as it is the case in the former examples. The utility achieved by the individual at time $i$ in the social state $\mathbf{s}$ is $U_{i}(\mathbf{s})=U\left(x_{i}, i\right)$, where $x_{i}>0$ is her income in period $i$ (see e.g. Bohren and Hansen (1980), Ekern (1981), Karcher, Moyes, and Trannoy (1995), Moyes (2011)). The model is formally identical to that in Example 5.2 as it can be seen by letting $\theta_{i}=i$, for all $i$. The assumption $U_{y}(y, i) \geqq 0$ represents intertemporal efficiency: more income at any point in her lifetime increases an individual's well-being. Impatience is captured by the condition that $U_{y}(y, i) \geqq U_{y}(y, i+1)$, for all $i=1,2, \ldots, n-1$ : other things equal, if an additional dollar is to be given, then the individual prefers to get it today than tomorrow. ${ }^{10}$ It follows from the discussion in Example 5.2 that utilitarian and welfarist unanimities may lead to different rankings of the intertemporal streams when the utility functions obey the two conditions above. Because it makes little sense in the absence of additional information about the state of the world at time $i$ to require that $U(y, i) \leqq U(y, i+1)$, for all $y>0$ and all $i=1,2, \ldots, n-1$, there seems to be no hope of reconciling utilitarian and welfarist unanimities here.

Example 5.5. Comparisons of Allocations in an Exchange Economy: Case 1. Consider an economy where $\ell$ commodities $(\ell \geqq 2)$ have to be distributed among $n$ individuals. A social state - or equivalently, an allocation - is a vector $\mathbf{s}:=\left(\mathbf{x}_{1}, \ldots, \mathbf{x}_{n}\right)$, where $\mathbf{x}_{i}:=$ $\left(x_{i 1}, \ldots, x_{i \ell}\right) \in \mathbb{R}_{++}^{\ell}$ is the bundle allocated to individual $i, x_{i h}$ is the quantity of commodity $h$ she receives, and $\mathscr{X}=\mathbb{R}_{++}^{\ell n}$ is the set of social states. We assume that the individuals transform these commodities into well-being by means of an identical utility function and, as in the previous examples, we suppose that they are selfish, hence $U_{i}(\mathbf{s})=U\left(\mathbf{x}_{i}\right)$, for all $i=1,2, \ldots, n$. We let $\ell=2$ to simplify and we indicate by $U_{1}(\mathbf{x})$ and $U_{2}(\mathbf{x})$ the first derivatives with respect to the first and second commodities, by $U_{11}(\mathbf{x})$ and $U_{22}(\mathbf{x})$ the second derivatives, by $U_{12}(\mathbf{x})$ the cross-derivative, and so on. Following Atkinson and Bourguignon (1982), we assume that

$$
U_{1}(\mathbf{x}) \geqq 0, U_{2}(\mathbf{x}) \geqq 0, \text { and } U_{12}(\mathbf{x}) \leqq 0, \forall \mathbf{x} \in \mathbb{R}_{++}^{2},
$$

and we let $\mathscr{U}^{*}$ be the class of all $n$-tuples of identical individual utility functions satisfying these three conditions. Letting $V(\mathbf{x})=\psi(U(\mathbf{x}))$ and upon differentiation, we obtain

$$
\begin{aligned}
& V_{h}(\mathbf{x})=\psi^{\prime}(U(\mathbf{x})) U_{h}(\mathbf{x}), \text { for } h=1,2 ; \text { and } \\
& V_{12}(\mathbf{x})=\psi^{\prime \prime}(U(\mathbf{x})) U_{1}(\mathbf{x}) U_{2}(\mathbf{x})+\psi^{\prime}(U(\mathbf{x})) U_{12}(\mathbf{x}) .
\end{aligned}
$$

Then, it is clear that

$$
V_{1}(\mathbf{x}) \geqq 0, V_{2}(\mathbf{x}) \geqq 0 \text { and } V_{12}(\mathbf{x}) \leqq 0, \forall \mathbf{x} \in \mathbb{R}_{++}^{2},
$$

\footnotetext{
${ }^{10}$ Another possible interpretation is to consider a distribution of income for a dynasty in which case the index $i$ will refer to generation $i$. Then, $\mathbf{s}:=\left(x_{1}, x_{2}, \ldots, x_{n}\right)$ is the intergenerational distribution of income of a dynasty comprising $n$ generations and $U_{i}(\mathbf{s})=U\left(x_{i}, i\right)$ is the utility derived by generation $i$. Impatience reflects in this case the fact that the well-being of the future generations is of little concern for the current generation.
} 
whenever conditions (5.7) hold and $\psi$ is non-decreasing and concave. Hence, the class $\mathscr{U}^{*}$ is closed under functional composition by all non-decreasing and concave functions, and we conclude that the application of unanimity to the utilitarian and welfarist principles lead to the same ranking of allocations.

On the other hand, Atkinson and Bourguignon (1982) have also considered the more restrictive class of profiles satisfying, in addition to those properties, the conditions that

$$
U_{11}(\mathbf{x}) \leqq 0, U_{22}(\mathbf{x}) \leqq 0, U_{112}(\mathbf{x}) \geqq 0, U_{221}(\mathbf{x}) \geqq 0 \text { and } U_{1122}(\mathbf{x}) \leqq 0, \forall \mathbf{x} \in \mathbb{R}_{++}^{2},
$$

and have derived a stochastic dominance criterion that is equivalent to utilitarian unanimity over that restricted class. Yet the class of all $n$-tuples of identical individual utility functions satisfying these assumptions is not closed under functional composition by all non-decreasing and concave functions. Indeed, we obtain:

$$
\begin{aligned}
V_{11}(\mathbf{x}) & =\psi^{\prime \prime}(U(\mathbf{x})) U_{1}(\mathbf{x})^{2}+\psi^{\prime}(U(\mathbf{x})) U_{11}(\mathbf{x}) \\
V_{22}(\mathbf{x}) & =\psi^{\prime \prime}(U(\mathbf{x})) U_{2}(\mathbf{x})^{2}+\psi^{\prime}(U(\mathbf{x})) U_{22}(\mathbf{x}) \\
V_{112}(\mathbf{x}) & =\psi^{\prime \prime \prime}(U(\mathbf{x})) U_{1}(\mathbf{x})^{2} U_{2}(\mathbf{x})+\psi^{\prime \prime}(U(\mathbf{x}))\left[2 U_{1}(\mathbf{x}) U_{12}(\mathbf{x})+U_{11}(\mathbf{x}) U_{2}(\mathbf{x})\right] \\
& +\psi^{\prime}(U(\mathbf{x})) U_{112}(\mathbf{x})
\end{aligned}
$$

$$
\begin{aligned}
V_{221}(\mathbf{x}) & =\psi^{\prime \prime \prime}(U(\mathbf{x})) U_{2}(\mathbf{x})^{2} U_{1}(\mathbf{x})+\psi^{\prime \prime}(U(\mathbf{x}))\left[2 U_{2}(\mathbf{x}) U_{21}(\mathbf{x})+U_{22}(\mathbf{x}) U_{1}(\mathbf{x})\right] \\
& +\psi^{\prime}(U(\mathbf{x})) U_{221}(\mathbf{x})
\end{aligned}
$$

$$
\begin{aligned}
V_{1122}(\mathbf{x}) & =\psi^{\prime \prime \prime \prime}(U(\mathbf{x})) U_{1}(\mathbf{x})^{2} U_{2}(\mathbf{x})^{2} \\
& +\psi^{\prime \prime \prime}(U(\mathbf{x}))\left[U_{1}(\mathbf{x})^{2} U_{22}(\mathbf{x})+4 U_{1}(\mathbf{x}) U_{2}(\mathbf{x}) U_{12}(\mathbf{x})+U_{2}(\mathbf{x})^{2} U_{11}(\mathbf{x})\right] \\
& +\psi^{\prime \prime}(U(\mathbf{x}))\left[2 U_{12}(\mathbf{x})^{2}+2 U_{1}(\mathbf{x}) U_{122}(\mathbf{x})+2 U_{2}(\mathbf{x}) U_{112}(\mathbf{x})+U_{11}(\mathbf{x}) U_{22}(\mathbf{x})\right] \\
& +\psi^{\prime}(U(\mathbf{x})) U_{1122}(\mathbf{x}) .
\end{aligned}
$$

Conditions (5.7) and (5.10) together with the assumption that $\psi$ is non-decreasing and concave are not sufficient to guarantee that

$$
V_{112}(\mathbf{x}) \geqq 0, V_{221}(\mathbf{x}) \geqq 0 \text { and } V_{1122}(\mathbf{x}) \leqq 0, \forall \mathbf{x} \in \mathbb{R}_{++}^{2} .
$$

Indeed, consider the utility function

$$
U\left(x_{1}, x_{2}\right)=\left(\frac{x_{1}^{0.25}+x_{2}^{0.25}}{2}\right)^{4},
$$

which verifies conditions (5.7) and (5.11). Choose

$$
\psi(u)=\frac{1}{2}(u-1)-\frac{1}{2}\left((u-1)^{2}+\frac{1}{10^{2}}\right)^{\frac{1}{2}},
$$

which is non-decreasing and concave and define $V\left(x_{1}, x_{2}\right)=\psi\left(U\left(x_{1}, x_{2}\right)\right)$. Then, it can be checked that

$$
V_{112}(\mathbf{x})<0, V_{221}(\mathbf{x})<0 \text { and } V_{1122}(\mathbf{x})>0, \forall \mathbf{x}=\left(x_{1}, x_{2}\right) \in(2.568,2.660)^{2} .
$$


It follows that the ranking of situations by welfarist unanimity when the social welfare function is non-decreasing and Schur-concave implies but is not implied by the ranking provided by the second dominance criterion proposed by Atkinson and Bourguignon (1982). We conclude that the latter criterion cannot be justified by requiring unanimity among all welfarist ethical observers with a concern for efficiency and equity as it is defined above. Additional restrictions have therefore to be placed on the social welfare function in order to ensure that unanimous agreement among all welfarist ethical observers will lead to a ranking of the situations under comparison identical to that implied by the second dominance criterion of Atkinson and Bourguignon (1982). ${ }^{11}$

Example 5.6. Comparisons of Allocations in an Exchange Economy: Case 2. We consider a distribution economy as in the preceding example but now we follow Kolm (1977) and assume that $U_{1}(\mathbf{x}) \geqq 0, U_{2}(\mathbf{x}) \geqq 0$, for all $\mathbf{x} \in \mathbb{R}_{++}^{2}$, and that $U$ is concave in the sense that

$$
U\left((1-\lambda) \mathbf{x}^{\circ}+\lambda \mathbf{x}^{*}\right) \geqq(1-\lambda) U\left(\mathbf{x}^{\circ}\right)+\lambda U\left(\mathbf{x}^{*}\right), \forall \mathbf{x}^{\circ}, \mathbf{x}^{*} \in \mathbb{R}_{++}^{2}, \forall 0 \leqq \lambda \leqq 1 .
$$

Let $V(\mathbf{x})=\psi(U(\mathbf{x}))$, for all $\mathbf{x} \in \mathbb{R}_{++}^{2}$, where $\psi$ is non-decreasing and concave. Thanks to the non-decreasingness and concavity of $\psi$, we obtain

$$
\begin{gathered}
V\left((1-\lambda) \mathbf{x}^{\circ}+\lambda \mathbf{x}^{*}\right)=\psi\left(U\left((1-\lambda) \mathbf{x}^{\circ}+\lambda \mathbf{x}^{*}\right)\right) \geqq \psi\left((1-\lambda) U\left(\mathbf{x}^{\circ}\right)+\lambda U\left(\mathbf{x}^{*}\right)\right) \geqq \\
(1-\lambda) \psi\left(U\left(\mathbf{x}^{\circ}\right)\right)+\lambda \psi\left(U\left(\mathbf{x}^{\circ}\right)\right)=(1-\lambda) V\left(\mathbf{x}^{\circ}\right)+\lambda V\left(\mathbf{x}^{*}\right),
\end{gathered}
$$

which holds for all $\mathbf{x}^{\circ}, \mathbf{x}^{*} \in \mathbb{R}_{++}^{2}$ and all $0 \leqq \lambda \leqq 1$. Thus $V$ is concave, something which in conjunction with the fact that it is also non-decreasing in each of its arguments implies that utilitarian and welfarist unanimities provide the same ranking of the social states under comparison.

\section{Discussion and Related Literature}

The closedness conditions identified in Propositions 4.1 and 4.2 constrain somewhat the classes of $n$-tuples of utility functions considered in the evaluation process. In particular, the examples discussed in Section 5 indicate that not every class of profiles satisfies these closedness conditions. The question then arises to know how informative are these closedness conditions about the richness of the class of profiles that is required for guaranteeing the congruence between utilitarian and the welfarist unanimities. The following, which is a direct consequence of Proposition 4.2, suggests an answer to that question:

Proposition 6.1. Let $\mathbf{s}^{*}, \mathbf{s}^{\circ} \in \mathscr{X}$ and $\boldsymbol{U}:=\left(U_{1}, \ldots, U_{n}\right) \in \mathscr{U}$ be given. Then, the following two statements are equivalent:

(a) $\sum_{i=1}^{n} \psi\left(U_{i}\left(\mathbf{s}^{*}\right)\right) \geqq \sum_{i=1}^{n} \psi\left(U_{i}\left(\mathbf{s}^{\circ}\right)\right)$, for all $\psi$ non-decreasing and concave.

(b) $G\left(\boldsymbol{U}\left(\mathbf{s}^{*}\right)\right) \geqq G\left(\boldsymbol{U}\left(\mathbf{s}^{\circ}\right)\right)$, for all $G$ non-decreasing and Schur-concave.

Hint. The proof of Proposition 6.1 is similar to that of Proposition 4.2 and it uses the fact that (b) is equivalent to $\boldsymbol{U}\left(\mathbf{s}^{*}\right) \geq_{G L} \boldsymbol{U}\left(\mathbf{s}^{\circ}\right)$ by Lemma 4.2. To prove that (a) implies (b), argue

${ }^{11}$ Certainly, if $\psi^{\prime \prime \prime}(u) \geqq 0$ and $\psi^{\prime \prime \prime \prime}(u) \leqq 0$, for all $u \in \mathbb{R}$, then condition (5.12) will hold. But then, we still need to identify the additional condition(s) that the social welfare function must satisfy for the analogue of Lemma 4.2 to hold with generalised Lorenz domination replaced by fourth order stochastic dominance. 
a contrario and show that not (b) - equivalently $\neg\left[\boldsymbol{U}\left(\mathbf{s}^{*}\right) \geq_{G L} \boldsymbol{U}\left(\mathbf{s}^{\circ}\right)\right]-\operatorname{implies}$ not (a). To prove that (b) implies (a), choose $G\left(u_{1}, \ldots, u_{n}\right)=\sum_{i=1}^{n} \psi\left(u_{i}\right)$ with $\psi$ non-decreasing and concave, and note that it is non-decreasing and Schur-concave. Then $G\left(\boldsymbol{U}\left(\mathbf{s}^{*}\right)\right) \geqq G\left(\boldsymbol{U}\left(\mathbf{s}^{\circ}\right)\right)$ reduces to $\sum_{i=1}^{n} \psi\left(U_{i}\left(\mathbf{s}^{*}\right)\right) \geqq \sum_{i=1}^{n} \psi\left(U_{i}\left(\mathbf{s}^{\circ}\right)\right)$, which holds true whatever the choice of $\psi$ non-decreasing and concave.

According to Proposition 6.1, in order to make sure that the utilitarian ranking of two social states coincides with that implied by all non-decreasing and Schur-concave social welfare functions, one has to adjust the profile. The adjustments of the profile are made by composing the individual utility functions with the non-decreasing and concave functions $\psi$. These transformations of the original profile may be considered the counterparts of the fact that the welfarist rule is defined up to the choice of the social welfare function $G$ provided it be non-decreasing and Schur-concave. To some extent the change in the curvature of the social indifference curves - in the utility space - corresponding to the choice of different non-decreasing and Schurconcave social welfare functions $G$ is reflected by a change in the individual utility functions accommodated through the $\psi$ functions. To make things more precise, given two situations $\mathbf{s}^{*}, \mathbf{s}^{\circ} \in \mathscr{X}$ and the profile $\boldsymbol{U}:=\left(U_{1}, \ldots, U_{n}\right) \in \mathscr{U}$, let $\mathbf{u}:=\left(u_{1}, \ldots, u_{n}\right)=\left(U_{1}\left(\mathbf{s}^{*}\right), \ldots, U_{n}\left(\mathbf{s}^{*}\right)\right)$ and $\mathbf{v}:=\left(v_{1}, \ldots, v_{n}\right)=\left(U_{1}\left(\mathbf{s}^{\circ}\right), \ldots, U_{n}\left(\mathbf{s}^{\circ}\right)\right)$ represent the corresponding distributions of utilities. Appealing to Lemma 4.2, we know that condition (b) in Proposition 6.1 is equivalent to $\mathbf{u} \geq_{G L} \mathbf{v}$, that is $\sum_{j=1}^{k} u_{(j)} \geqq \sum_{j=1}^{k} v_{(j)}$, for $k=1,2, \ldots, n$. This implies that there exist $n$ functions non-decreasing and concave $\psi^{k}$ such that $\sum_{j=1}^{n} \psi^{k}\left(u_{(j)}\right) \geqq \sum_{j=1}^{n} \psi^{k}\left(v_{(j)}\right)$, for $k=1,2, \ldots, n$. Indeed, choose

$$
\psi^{k}(s):=\left\{\begin{array}{cl}
s, & \forall s \leqq u_{(1)}+\cdots+u_{(k)}, \\
u_{(1)}+\cdots+u_{(k)}, & \forall u_{(1)}+\cdots+u_{(k)}<s,
\end{array}\right.
$$

which is non-decreasing and concave, for all $k=1,2, \ldots, n$. On a related side, it is interesting to note that, if one requires that $G$ is separable from its complement in addition to the fact that it is non-decreasing and Schur-concave, then one gets that

$$
G(\mathbf{u}) \geqq G(\mathbf{v}) \Longleftrightarrow \sum_{i=1}^{n} g\left(u_{i}\right) \geqq \sum_{i=1}^{n} g\left(v_{i}\right), \forall \mathbf{u}:=\left(u_{1}, \ldots, u_{n}\right), \mathbf{v}:=\left(v_{1}, \ldots, v_{n}\right) \in \mathbb{R}^{n},
$$

so that additivity of the social welfare function is not that far. ${ }^{12}$ However, while the requirement of unanimity is indispensable for Proposition 6.1 to hold, we insist on the fact that there is no need of any form of separability.

Throughout the paper we have restricted our attention to comparisons of social states for a given population. Our results extend easily to comparisons of societies with different numbers of individuals by invoking the principle of population due to Dalton (1920). Then, we have to consider a family of social welfare functions indexed by the population size $\left\{G^{n}\right\}$, where $G^{n}\left(u_{1}, \ldots, u_{n}\right)$ is the social welfare function for a population of $n$ individuals. Given the distribution of utilities $\mathbf{u}=\left(u_{1}, \ldots, u_{n}\right) \in \mathbb{R}^{n}$, we indicate by $\mathbf{u}^{q}=(\mathbf{u} ; \ldots ; \mathbf{u}) \in \mathbb{R}^{n q}$ its $q$-replication. Then, one requires that the family $\left\{G^{n}\right\}$ has the properties that $G^{n}$ is nondecreasing and Schur-concave, for all $n=2,3, \ldots, \infty$, and that it verifies in addition the principle of population according to which $G^{n q}\left(\mathbf{u}^{q}\right)=G^{n}(\mathbf{u})$, for all $\mathbf{u}=\left(u_{1}, \ldots, u_{n}\right) \in \mathbb{R}^{n}$, all $n \geqq 2$, and all $q \geqq 1$. In order to extend Propositions 4.1 and 4.2 we have to appeal to the

12 The proof of this assertion, which makes use of Gorman overlapping theorem, can be found in Blackorby and Shorrocks (1995, Chapter 12): we are indebted to a referee for drawing our attention to this result. 
definition of rank order (resp. generalised Lorenz) dominance based on the comparison of the quantile (resp. Lorenz) curves (see e.g. Moyes (1999)), and to substitute for the utilitarian social welfare function $\sum_{i=1}^{n} u_{i}$ the average utilitarian one defined by $\left(\sum_{i=1}^{n} u_{i}\right) / n$, for all $\mathbf{u}=\left(u_{1}, \ldots, u_{n}\right) \in \mathbb{R}^{n}$.

Finally, it is important to note that it is still an open question of whether our closedness conditions are also necessary for the equivalence between the utilitarian and welfarist unanimities to hold. It would obviously be nice to identify a closedness condition to be imposed on the class $\mathscr{U}^{*}$ that is both necessary and sufficient for the utilitarian and welfarist unanimity rankings of social states to coincide. However, there is little hope to obtain such a result at the level of generality of Propositions 4.1 and 4.2, where we refrained from making restrictive assumptions about the structure of the set of social states and the properties of the profiles. On the other hand, examination of our examples suggests that there might be a way out of this impossibility if one imposes a particular structure on the set of social states allowing utility to be connected with the characteristics of the social states.

Suppose as in Example 5.5 that $\mathscr{X}=\mathbb{R}_{++}^{\ell n}$, where $\ell$ is the number of attributes (income, wealth, private or public goods consumption), which we are interested in the distribution of, and let $\ell=2$ to simplify. A social state is a vector $\mathbf{s}:=\left(\mathbf{x}_{1}, \ldots, \mathbf{x}_{n}\right)$, where $\mathbf{x}_{i}:=\left(x_{i 1}, x_{i 2}\right) \in$ $\mathbb{R}_{++}^{2}$ is individual $i$ 's situation in state $\mathbf{s}$ and $x_{i h}$ her endowment of attribute $h$. Assume in addition that individuals care only about themselves and all have the same utility function so that $U_{i}(\mathbf{s})=U\left(\mathbf{x}_{i}\right)$, for all $i=1,2, \ldots, n$ and all $\mathbf{s} \in \mathscr{X}$. Let

$$
\overline{\mathscr{U}}:=\left\{\boldsymbol{U}:=(U, \ldots, U) \mid U_{12}(\mathbf{x}) \leqq 0, \forall \mathbf{x} \in \mathbb{R}_{++}^{2}\right\}
$$

be the set of admissible $n$-tuples of identical utility functions. Now, given the class of profiles $\mathscr{U}^{*} \subseteq \overline{\mathscr{U}}$, we claim that $\boldsymbol{\Psi}_{2}\left(\mathscr{U}^{*}\right) \subseteq \mathscr{U}^{*}$ is a necessary condition for $\sum_{i=1}^{n} U\left(\mathrm{x}_{i}^{*}\right) \geqq$ $\sum_{i=1}^{n} U\left(\mathbf{x}_{i}^{\circ}\right)$, for all profiles $\boldsymbol{U}:=(U, \ldots, U) \in \mathscr{U}^{*}$, to imply that $G\left(U\left(\mathbf{x}_{1}^{*}\right), \ldots, U\left(\mathbf{x}_{n}^{*}\right)\right) \geqq$ $G\left(U\left(\mathbf{x}_{1}^{\circ}\right), \ldots, U\left(\mathbf{x}_{n}^{\circ}\right)\right)$, for all profiles $\boldsymbol{U}:=(U, \ldots, U) \in \mathscr{U}^{*}$ and all social welfare functions $G$ non-decreasing and Schur-concave. One easily checks that the class of admissible profiles is non-empty: for instance it contains the $n$-tuples $\boldsymbol{U}:=(U, \ldots, U)$ such that $U\left(x_{1}, x_{2}\right)=\sqrt{x_{1}} / x_{2}, U\left(x_{1}, x_{2}\right)=x_{1} x_{2}$, or $U\left(x_{1}, x_{2}\right)=\sqrt{x_{1}+x_{2}}$. Thanks to our examples, we also know that there exist subsets in $\overline{\mathscr{U}}$ that are not closed under functional composition by all non-decreasing and concave functions. Formally, we have the following result:

Proposition 6.2. Let $\mathscr{U}^{*} \subseteq \overline{\mathscr{U}}$ and $\mathscr{G}^{*}=\mathscr{G}_{2}$. Then, a necessary and sufficient condition for (3.1) and (3.2) to be equivalent for any $\mathbf{s}^{*}, \mathbf{s}^{\circ} \in \mathscr{X}$ is that $\boldsymbol{\Psi}^{*}\left(\mathscr{U}^{*}\right) \subseteq \mathscr{U}^{*}$, where $\boldsymbol{\Psi}^{*}=\boldsymbol{\Psi}_{2}$.

Proof. We only have to prove that $\Psi_{2}\left(\mathscr{U}^{*}\right) \subseteq \mathscr{U}^{*}$ is necessary for condition (3.1) to imply condition (3.2), for all $\mathbf{s}^{*}, \mathbf{s}^{\circ} \in \mathscr{X}$. We argue a contrario and we show that, if $\neg\left[\boldsymbol{\Psi}_{2}\left(\mathscr{U}^{*}\right) \subseteq \mathscr{U}^{*}\right]$, then there exists a pair of social states $\mathbf{s}^{*}, \mathbf{s}^{\circ} \in \mathscr{X}$ for which

$$
\sum_{i=1}^{n} U\left(\mathbf{x}_{i}^{*}\right) \geqq \sum_{i=1}^{n} U\left(\mathbf{x}_{i}^{\circ}\right), \forall \boldsymbol{U}:=(U, \ldots, U) \in \mathscr{U}^{*},
$$

and at the same time

$$
\widetilde{G}\left(\widetilde{U}\left(\mathbf{x}_{1}^{*}\right), \ldots, \widetilde{U}\left(\mathbf{x}_{n}^{*}\right)\right)<\widetilde{G}\left(\widetilde{U}\left(\mathbf{x}_{1}^{\circ}\right), \ldots, \widetilde{U}\left(\mathbf{x}_{n}^{\circ}\right)\right),
$$

for some social welfare function $\widetilde{G} \in \mathscr{G}_{2}$ and some profile $\widetilde{\boldsymbol{U}}:=(\widetilde{U}, \ldots, \widetilde{U}) \in \mathscr{U}^{*}$. Since $\mathscr{U}^{*}$ is not closed under functional composition by all non-decreasing and concave functions, there exists a profile $\widetilde{\boldsymbol{U}}:=(\widetilde{U}, \ldots, \widetilde{U}) \in \mathscr{U}^{*}$ and a function $\widetilde{\psi} \in \boldsymbol{\Psi}_{2}$ such that $\widetilde{V}_{12}(s, t)>0$, for 
some $(s, t) \in \mathbb{R}_{++}^{2}$, where $\tilde{V}:=\widetilde{\psi} \circ \widetilde{U}$. Choose $\mathbf{s}^{\circ}=((s, t), \ldots,(s, t),(s, t),(s+\epsilon, t+\delta))$ and $\mathbf{s}^{*}=((s, t), \ldots,(s, t),(s+\epsilon, t),(s, t+\delta))$, where $\epsilon$ and $\delta$ are positive and arbitrarily small. Because $\mathscr{U}^{*} \subseteq \overline{\mathscr{U}}$, condition (6.3) necessarily holds. Now, choose $\widetilde{G}\left(u_{1}, \ldots, u_{n}\right):=\sum_{i=1}^{n} \widetilde{\psi}\left(u_{i}\right)$, for all $\left(u_{1}, \ldots, u_{n}\right) \in \mathbb{R}^{n}$, and observe that this social welfare function is non-decreasing and Schur-concave. However, we have

$$
\widetilde{G}\left(\widetilde{\boldsymbol{U}}\left(\mathbf{s}^{*}\right)\right)=\sum_{i=1}^{n} \widetilde{\psi} \circ \widetilde{U}\left(\mathbf{x}_{i}^{*}\right)=\sum_{i=1}^{n} \widetilde{V}\left(\mathbf{x}_{i}^{*}\right)<\sum_{i=1}^{n} \widetilde{V}\left(\mathbf{x}_{i}^{\circ}\right)=\sum_{i=1}^{n} \widetilde{\psi} \circ \widetilde{U}\left(\mathbf{x}_{i}^{\circ}\right)=\widetilde{G}\left(\widetilde{\boldsymbol{U}}\left(\mathbf{s}^{\circ}\right)\right),
$$

due to the fact that $\widetilde{V}_{12}(s, t)>0$, which makes the proof complete.

While Proposition 6.2 does not cover all the possibilities that may arise, it nevertheless demonstrates that in certain cases our closedness condition is both necessary and sufficient for utilitarian and welfarist unanimities to agree on the ranking of social states.

\section{Concluding Remarks}

The application of the utilitarian rule when comparing alternative social states generally conflicts with the rankings provided by more equity inclined welfarist principles like the maximin. We have shown in the paper that the imposition of unanimity permits one to reconcile admittedly under specific qualifications - these two conflicting principles. More precisely, we have identified two properties which, if satisfied by the class of utility profiles over which the utilitarian and the welfarist rules look for unanimity, ensure that the rankings of social states implied by these two principles coincide. When the degree of consensus sought in terms of welfarist unanimity is so large that it includes all symmetric and non-decreasing social welfare functions, it is sufficient that the class of profiles be closed under functional composition by all non-decreasing functions (Proposition 4.1). If one restricts the consensus in terms of welfarist unanimity to non-decreasing and Schur-concave social welfare functions, then the class of profiles must be closed under functional composition by all non-decreasing and concave functions for the welfarist and utilitarian unanimities to rank social states in the same way (Proposition $4.2)$.

From a technical perspective, these results are helpful to the extent that they permit one admittedly with some qualifications - to simplify a priori involved proofs. For instance, our results say that, if it has been proven that one situation (distribution of income, tax regime and the like) is considered to be better than another by all utilitarian social welfare functions, then there is no need to verify that this is also true for all non-decreasing and Schur-concave social welfare functions. It is sufficient to check that the class of profiles over which unanimity is looked for is closed under composition by all non-decreasing and concave functions.

Our results are of particular relevance for stochastic dominance analysis where one is looking for the rankings of distributions - be they of the unidimensional or multidimensional type by utilitarian unanimity. Given the intrinsic limitations of the utilitarian rule from an ethical point of view, it would be interesting to know if the standard results continue to hold when less debatable principles are substituted for the utilitarian one. Dasgupta et al. (1973) have shown that both the specific utilitarian approach and the more general welfarist ones lead to the same dominance criteria in the very special case where all individuals have the same utility function and income is the only variable entering the utility function. Yet the question arises as to whether their result extends to a more general framework and in particular to the comparison of multidimensional distributions. Proposition 6.2 certifies that such extension is possible when 
there are two attributes and when all individuals are endowed with the same non-decreasing utility function whose cross-derivatives are non-positive. While this result does not exhaust all the possibilities, it nevertheless suggests that relying exclusively on the utilitarian social welfare function for conducting stochastic dominance analysis is not as restrictive as it might look at first sight.

Our readers might be frustrated by realising that we have only proven that our closedness conditions are sufficient for the utilitarian and welfarist unanimities to coincide. While we have shown that in particular cases these closedness conditions are also necessary (see Proposition 6.2 ), we have to admit that it is an open question whether they are also necessary in the general case. Examination of the proofs suggests however that there is little hope of proving necessity in the absence of additional restrictions being placed on the utility profiles as well as on the set of social states.

\section{References}

Atkinson, A. B. (1970). On the measurement of inequality. Journal of Economic Theory, 2, $244-263$.

Atkinson, A. B. (1981). The measurement of economic mobility. In P. Eijgelshoven and L. van Gemerden, editors, Inkomensverdeling en Openbare Financiën: Opstellen voor Jan Pen, pages 9-24. Uitgeverij Het Spectrum, Utrecht/Antwerpen.

Atkinson, A. B. and Bourguignon, F. (1982). The comparison of multidimensioned distributions of economic status. Review of Economic Studies, 49, 183-201.

Atkinson, A. B. and Bourguignon, F. (1987). Income distributions and differences in needs. In G. Feiwel, editor, Arrow and the Foundations of the Theory of Economic Policy, pages 350-370. Macmillan, New York.

Basu, K. and Mitra, T. (2007). Utilitarianism for infinite utility streams: A new welfare criterion and its axiomatic characterization. Journal of Economic Theory, 133, 350-373.

Bazen, S. and Moyes, P. (2003). International comparisons of income distributions. Research on Economic Inequality, 9, 85-111.

Blackorby, C. and Donaldson, D. (1977). Utility vs equity: Some plausible quasi-orderings. Journal of Public Economics, 7, 365-382.

Blackorby, C. and Donaldson, D. (1982). Ratio-scale and translation-scale full interpersonnal comparability without domain restrictions: Admissible social evaluation functions. International Economic Review, 23, 249-268.

Blackorby, C. and Donaldson, D. (1993). Adult-equivalence scales and the economic implementation of interpersonal comparisons of well-being. Social Choice and Welfare, 10, 335-361.

Blackorby, C. and Shorrocks, A. F. (1995). Separability and Aggregation: The Collected Works of W.M. Gorman, Volume 1. Clarendon Press, Oxford.

Blackorby, C., Bossert, W., and Donaldson, D. (2005). Population Issues in Social Choice Theory, Welfare Economics, and Ethics. Cambridge University Press, New York.

Bohren, O. and Hansen, T. (1980). Capital budgeting with unspecified discount rates. Scandinavian Journal of Economics, 82, 45-58. 
Bourguignon, F. (1989). Family size and social utility: Income distribution dominance criteria. Journal of Econometrics, 42, 67-80.

Dalton, H. (1920). The measurement of the inequality of incomes. Economic Journal, 30, $348-361$.

Dasgupta, P., Sen, A. K., and Starrett, D. (1973). Notes on the measurement of inequality. Journal of Economic Theory, 6, 180-187.

d'Aspremont, C. and Gevers, L. (2002). Social welfare functionals and interpersonal comparability. In K. Arrow, A. K.Sen, and K. Suzumura, editors, Handbook of Social Choice and Welfare, Volume I, pages 459-542. Elsevier/North-Holland, Amsterdam/New York/Oxford.

Ebert, U. (2004). Social welfare, inequality, and poverty when needs differ. Social Choice and Welfare, 23, 415-448.

Ebert, U. and Moyes, P. (2009). Household decision and equivalence scales. Journal of Population Economics, 22, 1039-1062.

Ekern, S. (1981). Time dominance efficiency analysis. The Journal of Finance, 36, 1023-1034.

Fishburn, P. C. and Vickson, R. G. (1978). Theoretical foundations of stochastic dominance. In G. Whitmore and M. Findlay, editors, Stochastic Dominance, pages 39-113. Lexington Books, Lexington, MA.

Fleurbaey, M., Hagneré, C., and Trannoy, A. (2003). Welfare comparisons with bounded equivalence scales. Journal of Economic Theory, 110, 309-336.

Fleurbaey, M., Hagneré, C., and Trannoy, A. (2007). Welfare comparisons of income distributions and family size. IDEP Discussion Paper 07-02, CNRS-EHESS-Universités AixMarseille II et III.

Foster, J. E. and Shorrocks, A. F. (1988). Poverty orderings and welfare dominance. Social Choice and Welfare, 5, 91-110.

Gravel, N. and Moyes, P. (2010). Ethically robust comparisons of bidimensional distributions with an ordinal attribute. Paper presented at the ParisTech-Journal of Economic Theory Conference on Inequality and Risk, Paris, June 25-26, 2010.

Gravel, N. and Moyes, P. (2011). Bidimensional inequalities with an ordinal variable. In M. Fleurbaey, M. Salles, and J. A. Weymark, editors, Social Ethics and Normative Economics. Essays in Honour of Serge-Christophe Kolm, pages 101-127. Springer-Verlag, Berlin Heidelberg.

Griffin, J. (1986). Well-Being, Its Meaning, Measurement and Moral Importance. Clarendon Press, Oxford.

Hadar, J. and Russell, W. (1969). Rules for ordering uncertain prospects. American Economic Review, 59, 25-34.

Hadar, J. and Russell, W. (1974). Stochastic dominance in choice under uncertainty. In M. Balch, D. McFadden, and S. Wu, editors, Essays on Economics Behavior under Uncertainty, pages 135-150. North-Holland, Amsterdam.

Hardy, G. H., Littlewood, J. E., and Pólya, G. (1934). Inequalities. Cambridge University Press, Cambridge.

Jenkins, S. P. and Lambert, P. J. (1993). Ranking income distributions when needs differ. 
Review of Income and Wealth, 39, 337-356.

Karcher, T., Moyes, P., and Trannoy, A. (1995). The stochastic dominance ordering of income distributions over time: The discounted sum of the expected utilities of incomes. In W. A. Barnett, H. Moulin, M. Salles, and N. J. Schofield, editors, Social Choice, Welfare and Ethics, pages 374-408. Cambridge University Press, Cambridge.

Kolm, S.-C. (1969). The optimal production of social justice. In J. Margolis and H. Guitton, editors, Public Economics, pages 145-200. Macmillan, London.

Kolm, S.-C. (1977). Multidimensional egalitarianisms. Quarterly Journal of Economics, 91, $1-13$.

Le Breton, M. (1987). Stochastic dominance: A bibliographical rectification and a restatement of Whitmore's theorem. Mathematical Social Sciences, 13, 73-79.

Madden, P. (1996). Suppes-Sen dominance, generalised Lorenz dominance and the welfare economics of competitive equilibrium: Some examples. Journal of Public Economics, 61, $247-262$.

Marshall, A. W. and Olkin, I. (1979). Inequalities: Theory of Majorization and its Applications. Academic Press, New York.

Marshall, A. W., Olkin, I., and Arnold, B. C. (2011). Inequalities: Theory of Majorization and its Applications. Springer, New York, second edition.

Mirrlees, J. A. (1971). An explanation in the theory of optimum income taxation. Review of Economic Studies, 38, 175-208.

Moyes, P. (1999). Stochastic dominance and the Lorenz curve. In J. Silber, editor, Handbook of Income Inequality Measurement, pages 199-222. Kluwer Academic Publishers, Boston/Dordrecht/London.

Moyes, P. (2011). Rearrangements and sequential rank order dominance: A result with economic applications. GREThA, Université Montesquieu Bordeaux IV.

Roemer, J. E. (1996). Theories of Distributive Justice. Harvard University Press, Cambridge, USA.

Rothschild, M. and Stiglitz, J. E. (1973). Some further results on the measurement of inequality. Journal of Economic Theory, 6, 188-204.

Saposnik, R. (1981). Rank-dominance in income distributions. Public Choice, 36, 147-151.

Saposnik, R. (1983). On evaluating income distributions: Rank dominance, the Suppes-Sen grading principle of justice, and Pareto optimality. Public Choice, 40, 329-336.

Sen, A. K. (1973). On Economic Inequality. Clarendon Press, Oxford.

Sen, A. K. (1977). On weights and measures: Informational constraints in social welfare analysis. Econometrica, 45, 1539-1572.

Sen, A. K. (1979a). Personal utilities and public judgements: Or what's wrong with welfare economics? The Economic Journal, 89, 537-558.

Sen, A. K. (1979b). Utilitarianism and welfarism. Journal of Philosophy, 76, 463-469.

Shorrocks, A. F. (1983). Ranking income distributions. Economica, 50, 3-17.

Shorrocks, A. F. (2004). Inequality and welfare evaluation of heterogeneous income distribu- 
tions. Journal of Economic Inequality, 2, 193-218.

Shorrocks, A. F. and Foster, J. E. (1987). Transfer sensitive inequality measures. Review of Economic Studies, 54, 485-497.

Van de gaer, D. (1993). Equality of Opportunity and Investment in Human Capital. Ph.D. thesis, Katholieke Universiteit Leuven, Leuven, Belgium.

Whitmore, G. (1970). Third-degree stochastic dominance. American Economic Review, 60, 457-459. 


\title{
Cahiers du GREThA Working papers of GREThA
}

\author{
GREThA UMR CNRS 5113 \\ Université Montesquieu Bordeaux IV \\ Avenue Léon Duguit \\ 33608 PESSAC - FRANCE \\ Tel : +33 (0)5.56.84.25.75 \\ Fax : +33 (0)5.56.84.86.47 \\ http://gretha.u-bordeaux4.fr/
}

\section{Cahiers du GREThA (derniers numéros)}

2011-16: BLANCHETON Bertrand, MARCHI Jean-Jacques, Le tourisme ferroviaire en France, une mise en perspective historique de 1870 à nos jours

2011-17 : BELIN Jean, HORBACH Jens, OLTRA Vanessa, Determinants and Specificities of Ecoinnovations -An Econometric Analysis for the French and German Industry based on the Community Innovation Survey

2011-18 : MARTIN Jean-Christophe, BECUWE Stéphane, Analyse de décomposition structurelle des émissions de gaz à effet de serre : application à la région Aquitaine

2011-19 : ROUILLON Sébastien, Solving the hotelling model in feedback form

2011-20 : FRIGANT Vincent, French mega-suppliers' trajectories during the modular era: some evidences on Faurecia, Valeo and Plastic Omnium

2011-21 : BECUWE Stéphane, BLANCHETON Bertrand, La dispersion des tarifs douaniers selon la provenance des produits (1850-1913) : illustration à travers le cas de la France

2011-22 : CARAYOL Nicolas, LAHATTE Agenor, Dominance relations when both quantity and quality matter, and applications to the comparison of US research universities and worldwide top departments in economics

2011-23 : MOYES Patrick, Comparisons of Heterogeneous Distributions and Dominance Criteria

2011-24 : BECUWE Stéphane, BLANCHETON Bertrand, Politique commerciale et croissance entre 1850 et 1913, Synthèse critique des contributions

2011-25 : PETIT Emmanuel, TCHERKASSOF Anna, GASSMANN Xavier, Anticipated regret and selfesteem in the Allais paradox

2011-26 : BONNEFOND Céline, CLEMENT Matthieu, An analysis of income polarization in rural and urban China

2011-27 : FRIGANT Vincent, Egyptian pyramid or Aztec pyramid: How should we describe the industrial architecture of automotive supply chains in Europe?

2011-28 : BEN MIM Sami, MABROUK Fatma, Transferts des migrants et croissance économique : quels canaux de transmission?

2011-29 : MABROUK Fatma, Migration de retour, de la théorie à la pratique

2011-30 : MOYES Patrick, GRAVEL Nicolas, Utilitarianism or Welfarism: Does it Make a Difference?

La coordination scientifique des Cahiers du GREThA est assurée par Sylvie FERRARI et Vincent FRIGANT. La mise en page est assurée par Anne-Laure MERLETTE. 